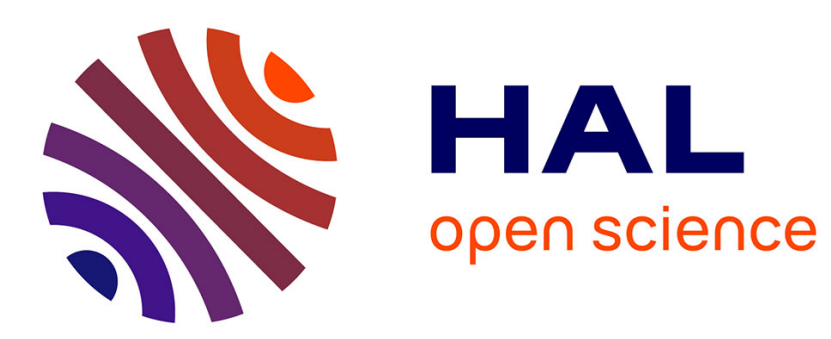

\title{
Thermal modelling of a car alternator with claw poles using 2D finite element software
}

S. Brisset, Michel Hecquet, P. Brochet

\section{To cite this version:}

S. Brisset, Michel Hecquet, P. Brochet. Thermal modelling of a car alternator with claw poles using 2D finite element software. COMPEL: The International Journal for Computation and Mathematics in Electrical and Electronic Engineering, 2001. hal-01731167

\section{HAL Id: hal-01731167 \\ https://hal.science/hal-01731167}

Submitted on 13 Mar 2018

HAL is a multi-disciplinary open access archive for the deposit and dissemination of scientific research documents, whether they are published or not. The documents may come from teaching and research institutions in France or abroad, or from public or private research centers.
L'archive ouverte pluridisciplinaire HAL, est destinée au dépôt et à la diffusion de documents scientifiques de niveau recherche, publiés ou non, émanant des établissements d'enseignement et de recherche français ou étrangers, des laboratoires publics ou privés. 


\title{
Thermal modelling of a car alternator with claw poles using 2D finite element software
}

\author{
S. Brisset ${ }^{1}$, M. Hecquet ${ }^{2}$ and P. Brochet $^{2}$ \\ L2EP \\ ${ }^{1}$ Ecole des Hautes Etudes Industrielles - 13, rue de Toul - 59046 Lille Cedex - France \\ ${ }^{2}$ Ecole Centrale de Lille - Cité scientifique - BP 48 - 59651 Villeneuve d'ascq Cedex - France \\ stephane.brisset@hei.fr - hecquet@ec-lille.fr - brochet@ec-lille.fr
}

\begin{abstract}
A car alternator with claw poles is typically a 3D device because its shape is not axi-symmetrical nor XYsymmetrical. A 3D finite element model can be useful to simulate the thermic behavior of the machine but is rarely available. In this paper, it is shown that a $2 D$ simulation can fit even if all the thermal phenomenon relating to the missing direction are neglected. The alternator have been modeled in two different sections to show their respective reliability. Moreover, thermal hybrid conductivities have been defined to take into account the succession of the different materials in the missing direction.
\end{abstract}

Keywords : thermal modelization, car alternator, claw pole, finite element model, Kirchhoff network, thermal hybrid conductivity.

\section{Introduction}

Interest

Electric machines generate heat, which is harmful to their life and increases the price of electric insulator. So, it appears necessary to model the thermal behavior of the electric machines, especially during the design process.

This study is part of a search for the reduction of the noise of the car alternators. Previous works showed the influence of the shape of claw poles on the acoustic disturbances of electromagnetic origin (Hecquet, 1995). Our objective is to foresee the influence of any modification of the shape of the machine on the distribution of temperatures.

\section{$2 D$ Finite element model}

The research has been conducted on the finite element software Opera2D, in thermal static regime (Vector Fields, 1999). Indeed, a software for thermal simulation in 3D is not always available and, even though it is case, leads to very high times of study and simulation because of the complexity of the geometry and the thermal phenomena which occur in the machine.

The use of a software for thermal simulation in $2 \mathrm{D}$ can justify itself in case geometry is invariant by translation (XY-symmetrical) or invariant by rotation (axisymmetrical). However, the whole geometry of an alternator with claw poles does not present any invariability even though some parts of the machine are invariant by rotation or translation (Fig. 1). In chapter 3, two sections are used to model the thermal behavior of the car alternator. The thermal exchanges, described in chapter 2 , will be more or less well taken into account according to the considered section.

To by-pass this problem, hybrid thermal conductivities are introduced in chapter 4 . Finally, obtained results are satisfactory with an average error equal to $8 \%$ as we shall see it in chapter 5 .

\section{Kirchhoff network}

The modeling using the finite element method brings accurate results for a significant computation time. However, it is also possible to obtain results of a satisfactory precision by using a Kirchhoff network because of the analogy which exists between electrical and thermal equations.

The thermal modelling using finite element puts in evidence the zones where temperature varies little and those with a significant gradient of temperature. The zones of constant temperature will become the nodes of a Kirchhoff network, voltage in these nodes is equal to the average temperature of the zone. The nodes are connected by resistors corresponding with thermal exchanges. Current and voltage drop across them are respectively equal to the heat flux and gradient of temperature.

The use of a Kirchhoff networks for the thermal study of electric machines is frequent and leads to good results (Bertin, 1998) (Glises, 1998). Here, the use of a finite

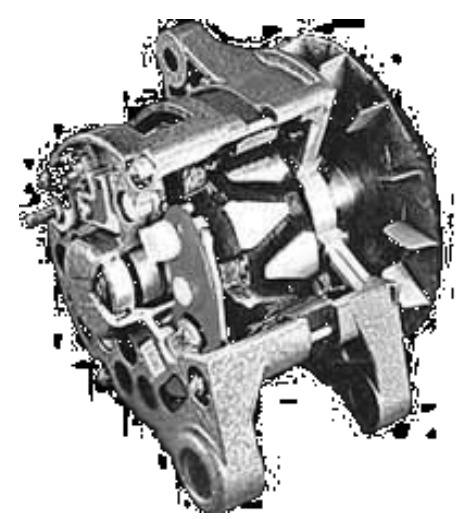

Fig. 1. Car alternator with claw poles. 
element software enables a topological description of the network by observing zones having a significant gradient of temperature. Finally, the obtained network possesses a reduced number of resistors and remains, nevertheless, accurate.

\section{The thermal exchanges}

A thermal simulation needs to determine the origin and magnitude of the heat sources and to define the nature of the thermal exchanges. The heat sources are the copper losses in the rotor winding, the copper losses in the stator windings and the iron losses in the stator sheet metal. They are calculated analytically or computed with a magnetic simulation. Three kinds of thermal transfers occur: conduction, convection and radiation (Fig. 2).

\section{Conduction}

The ability of a material to exchange heat with another material in contact and to conduct heat is given by its thermal conductivity $\lambda$ in $\mathrm{W} / \mathrm{m}$.K. It is expressed with a tensor of 3 components.

Heat conduction occurs in the rotor winding, the rotor crown, the claw poles, the shaft, the stator winding, the stack of sheet metal in the stator, the frame and the electric insulator inside the stator slots (Fig. 3). The thermal contact between solid materials is assumed to be perfect.

Some materials, like the stack of sheet metal and the windings are anisotropic. Indeed, the stack of sheet metal have a thermal conductivity lower in the $\mathrm{Z}$ direction than in the two other directions because there is a coat of varnish between the sheets. In the same way, the windings have a thermal conductivity higher in the $\mathrm{L}$ direction that in the other directions (Fig. 4). Other materials are isotropic.

\section{Convection}

A gradient of temperature between a surface and a fluid of cooling or even inside the fluid itself generates some thermal exchanges by transfers, resulting inboth natural convection and forced convection. In our study, the cooling of the alternator is made by a fan fixed on the rotor (forced convection), the cool air is coming from the outside: the

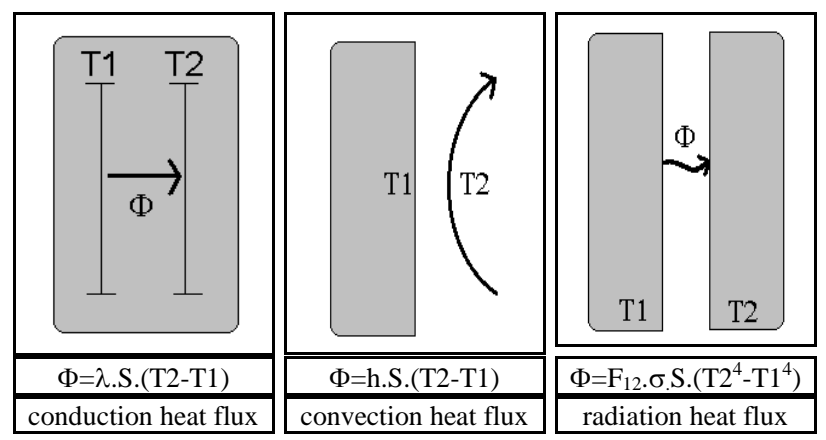

Fig. 2. The thermal exchanges.

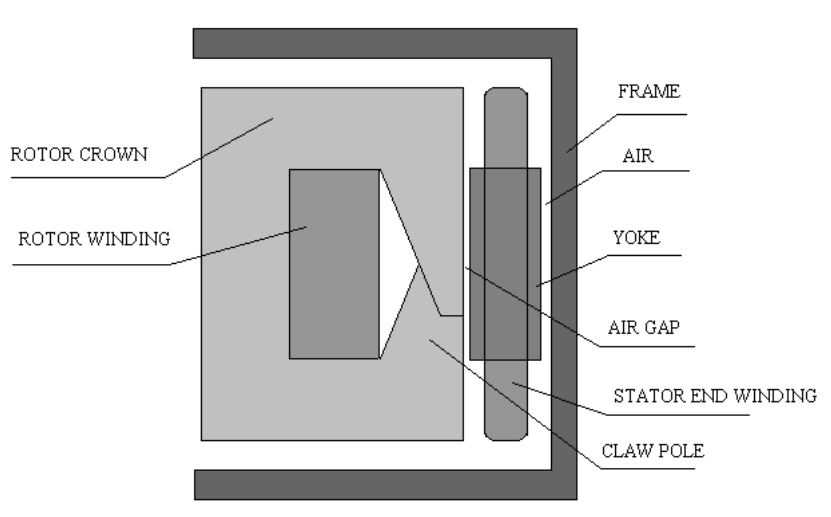

Fig. 3. Schematic shape of the car alternator.
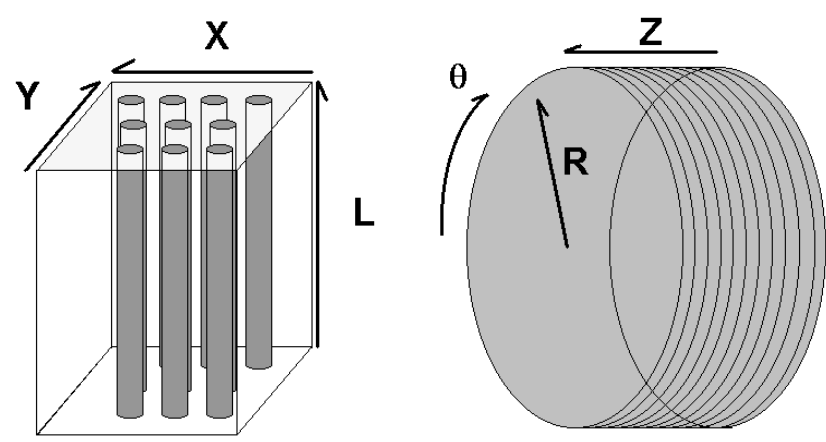

Fig. 4. Materials with anisotropic conductivity.

alternator is called "opened". The parameter used for our model with Opera2D is the convective coefficient $h$ in $\mathrm{W} / \mathrm{m}^{2}$.K. It depends on the geometry of the machine, on the cooling temperature and on the speed of the fluid. There are relations giving the values of this coefficient. They are computed using Reynolds, Grashof and Nusselt numbers (Sacadura, 1982).

Convection occurs on the surfaces of every solid material in contact with air. The estimation of the air speed on every surface of the alternator materials is difficult and leads to errors on the calculation of the convection coefficients.

The air gap and the air between the yoke and the frame are too thin so that the phenomenon of convection can not occur (Fig. 3). Therefore, these regions have been modeled as pure conduction materials. The claw poles of the rotor and the stator slots create some disturbances inside the fluid (some turbulences may appear) which improves the heat fluxes. To take this into account, the thermic conductivity of the air gap has been increased by $20 \%$ (Ziouchi, 1996).

\section{Radiation}

The heat transfer by radiation represents an exchange by way of electromagnetic waves between two bodies separated by a medium whose absorption could be neglected. 
This heat transfer takes place mainly in the air gap, in the air between the yoke and the frame and on the outer surface of the frame (Fig. 3). The quantity of radiated heat depends on the temperature of the surfaces.

Opera2D doesn't take into account this phenomenon. In order to get round this problem, the thermal conductivity of the air gap and the air between the yoke and the frame have been "boosted". For these regions, a global conductivity which represents the fluxes of conduction and radiation is defined. The expression of the thermal conductivity corresponding to the radiation is :

$$
\lambda_{\text {rad }}=R_{\text {rotor }} \cdot \ln \left(\frac{R_{\text {stator }}}{R_{\text {rotor }}}\right) \cdot \sigma \cdot\left(T_{\text {stator }}{ }^{2}+T_{\text {rotor }}{ }^{2}\right) \cdot\left(T_{\text {stator }}+T_{\text {rotor }}\right)
$$

$\mathrm{R}$ are the radius, $\sigma$ is Stéfan's constant and $\mathrm{T}$ are the temperatures.

For the radiation taking place on the outer surface of the frame, the radiation flux is expressed as a flux of convection. The global convection coefficient corresponding to the radiation is expressed as :

$$
h_{\text {rad }}=S_{12} \cdot \sigma \cdot\left(T_{\text {frame }}+T_{\text {fluid }}\right) \cdot\left(T_{\text {frame }}{ }^{2}+T_{\text {fluid }}{ }^{2}\right)
$$

$S_{12}$ is the shape factor depending on facing surfaces.

\section{Choice of the section}

In $3 \mathrm{D}$, the alternator is represented completely. So, all the heat exchanges are modeled. In $2 \mathrm{D}$, the machine is represented in a section. This section may be XYsymmetrical or axi-symmetrical. Each of the two sections presents some drawbacks. First of all, these representations involve the invariability of temperature and no propagation of heat in the missing direction. On the other hand, all the phenomena of convection could not be represented in every sections.

\section{$X Y$-symmetrical section}

Some regions of the alternator are invariant by translation. They are the stack of sheet metal, the electric insulators and the shaft (Fig. 5). The other regions are partially invariant as the stator windings and the frame. Indeed, the part of the windings located in slots is invariant by translation, but the windings ends are not. Also, the cylindrical part of the frame is visible in this section but not its lateral parts. This last point is a problem because the winding ends overhang the frame and are well ventilated. They dissipate a lot of heat by convection.

Because the winding ends are not visible in this section, we chose to remove copper losses corresponding to them. The representation of the frame is uncertain: is it necessary to increase the convection coefficient of the outer surface of the frame by using the ratio of the real surface of the frame to the surface visible in the XY-symmetrical section ? We chose not to do so because the simulation of the thermal behavior in this section implies that there is no heat exchange in direction $\mathrm{Z}$.

For regions not invariant by translation or placed on a common area in the XY-symmetrical section, hybrid thermic conductivities allow to take into account a succession of materials in direction $\mathrm{Z}$. These materials have generally different conductivities. Hybrid thermal conductivities are also used if the length of materials in direction $\mathrm{Z}$ is different from that of the stack of sheet metal.

It is necessary to note that conductivities are defined according to direction $\mathrm{X}$ and $\mathrm{Y}$ in Opera2D software. Hybrid thermal conductivities are calculated in the radial and tangential directions ( $R$ and $\theta$ ). This difference is not important if the fraction of the represented machine has a weak angular opening (Fig. 5).

Many thermal exchanges by convection and radiation are not taken into account. They occur on the outside surfaces of the rotor crowns, the winding ends and the lateral faces of the stack of sheet metal and the frame.

\section{Axi-symmetrical section}

This section is the most appropriate to take into account convective phenomenon because all the surfaces exchanging heat with the cooling fluid are represented.

The invariant regions by rotation are the shaft, the yoke, the rotor winding (Fig. 6). The frame possesses several openings for ventilation and is not so perfectly invariant. The rotor crowns are invariant excepted claw poles. Thanks to hybrid thermal conductivities, this problem is by-passed. For example, a thermal hybrid conductivity is defined for the succession of the following materials: the copper of the stator winding inside slots, iron of the stator teeth and electric insulation. It is a tensor of 2 components

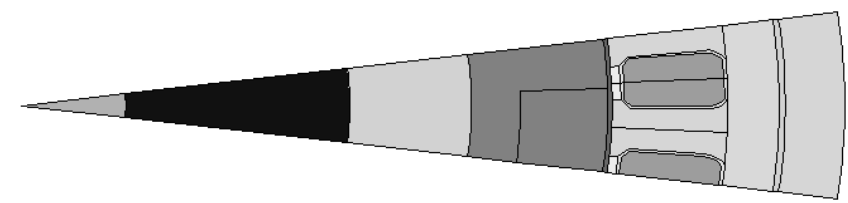

Fig. 5. XY-symmetrical section of the car alternator.

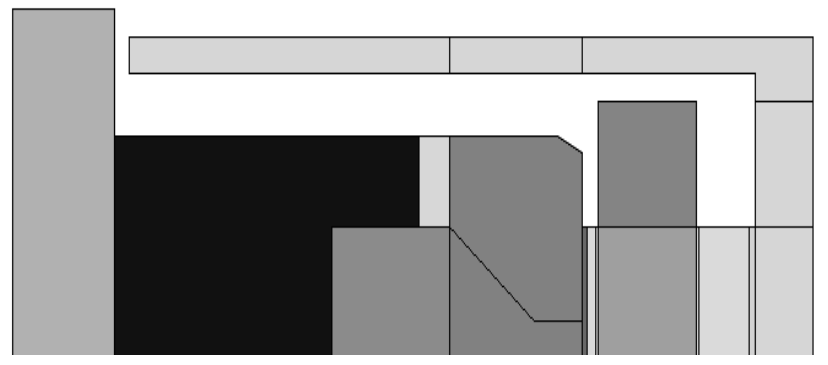

Fig. 6. Axi-symmetrical section of the car alternator. 
because the conductivities of sheet metal as those of the winding are different according to directions $\mathrm{R}$ and $\mathrm{Z}$.

\section{Thermal hybrid conductivity}

The sections sweep different regions depending on the value of the missing direction. Unfortunately, it is not possible to consider this succession of different materials. However, it could be taken into account by calculating, for the regions concerned by this problem, some thermal hybrid conductivities. Based on the analogy between thermal and electrical equations, a thermal resistor is defined for each material :

$$
R=\frac{L}{\lambda \cdot S}
$$

$\mathrm{L}$ is the length of material and $\mathrm{S}$ is the heat flux section.

The succession of the different materials in the missing direction enables the development of a network of resistors. The calculation of the equivalent resistor gives the thermal equivalent or hybrid conductivity.

For example, the calculation of the thermal hybrid conductivity corresponding to regions included between the inner radius and the outer radius of the rotor winding is detailed (Fig. 7). These regions are invariant by rotation, so the use of a hybrid conductivity justifies itself only for the $\mathrm{XY}$-symmetrical section.

The thermal resistor of the portion of rotor crown drawn in Fig. 7 and that of rotor winding are expressed in Eq. (4-

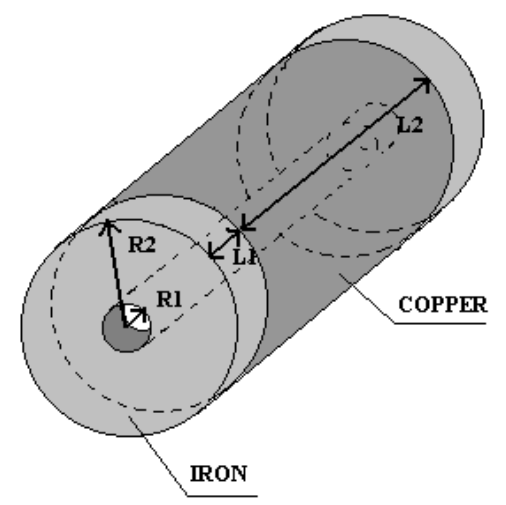

Fig. 7. Regions between inner and outer radius of the rotor winding.

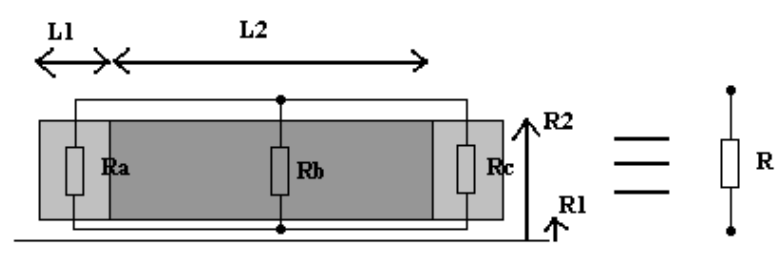

Fig. 8. Thermal hybrid conductivity of regions in Fig. 7.
$5)$.

$$
\begin{aligned}
& R_{a}=R_{c}=\frac{\ln \left(\frac{R_{2}}{R_{1}}\right)}{\lambda_{\text {iron }} \cdot 2 \pi \cdot L_{1}} \\
& R_{b}=\frac{\ln \left(\frac{R_{2}}{R_{1}}\right)}{\lambda_{\text {winding }} \cdot 2 \pi \cdot L_{2}}
\end{aligned}
$$

The winding conductivity $\lambda_{\text {winding }}$ takes two different values for directions $\mathrm{R}$ and $\theta$ contrary to $\lambda_{\text {iron }}$.

The thermal equivalent resistor is computed from three thermic resistances (Fig. 8) using Eq. (6) and allows to calculate the thermic hybrid conductivity $\lambda_{\text {hybrid }}$ as shown in Eq. (7) :

$$
\begin{aligned}
& \frac{1}{R}=\frac{1}{R_{a}}+\frac{1}{R_{b}}+\frac{1}{R_{c}} \\
& \lambda_{\text {hybrid }}=\frac{\ln \left(\frac{R_{2}}{R_{1}}\right)}{R \cdot 2 \pi \cdot L_{\text {stackof sheetmetal }}}
\end{aligned}
$$

This simple example well illustrates the principle of hybrid thermic conductivities. However, its application for regions of complex geometry as claw poles is sometimes laborious.

\section{Results}

The thermic conduction and convection parameters, respectively $\lambda$ and $h$, are calculated by assuming a temperature distribution on the surfaces and the cooling fluid. This enables the simulation of the thermal behavior of the alternator with Opera2D. If the resultant temperatures computed are equal to the assumed surface temperatures, then the parameters $\mathrm{h}$ and $\lambda$ are correct. Otherwise, it is necessary to iterate until a sufficiently accurate solution is obtained.

\section{$X Y$-symmetrical section}

In this section, the temperatures computed are always $100 \%$ higher than the experimental temperatures as shown in Table I. These results were predictable. Indeed, the XYsymmetrical section doesn't take into account the axial heat fluxes. The thermal axial conductivity of the stator windings is high, this means that the propagation of heat is made in priority in this direction. Moreover, this section doesn't take the convective exchanges into account on the lateral faces of the rotor, nor on the end windings. They are essential in the thermal behavior of the machine, because 
they are well ventilated and therefore the seat of important dissipations.

On the other hand, one observes in Fig. 9 that temperature is nearly constant following direction $\theta$ but varies strongly according to direction $R$. The thermic modelling in the axi-symmetric section gives the best results.

\section{Axi-symmetrical section}

On Fig. 10 are the temperatures computed with Opera2D. The comparison of computed values with the experimental ones shows a mean error equal to $8 \%$. Thermic hybrid conductivities are used for the stator end windings, the stator teeth and windings, and the claw poles to take into account the succession of different materials in the $\theta$ direction.

It is shown, on Table II, that temperatures calculated in the stator is superior to the experimental value while the temperature of the frame is lower. The increase of the conductivity of the layer of air between yoke and frame

\begin{tabular}{|l|c|c|c|}
\hline Temperatures & Opera2D - XY & Experiment & Error \\
\hline \multirow{2}{*}{$\begin{array}{l}\text { Stator winding } \\
\text { inside slots }\end{array}$} & 426 & 186,7 & $128,2 \%$ \\
\cline { 2 - 4 } & 426 & 178,9 & $138,1 \%$ \\
\hline Frame & 373 & 130,2 & $186,5 \%$ \\
\hline Stator teeth & 404 & 167,7 & $140,9 \%$ \\
\hline
\end{tabular}

Table I. Temperatures at different points of the car alternator. The first column is for temperatures computed using Opera2D in XY-symmetrical section, the second column is for experimental temperatures and the third column is the error between computation and experiment in percent.

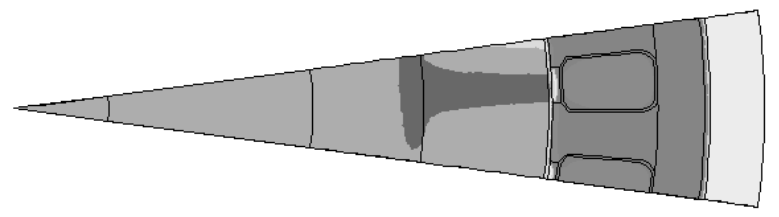

Fig. 9. Temperatures computed with Opera2D in XYsymmetrical section.

would decrease both errors.

\begin{tabular}{|l|c|c|c|}
\hline Temperatures & Opera2D - AXI & Experiment & Error \\
\hline \multirow{2}{*}{$\begin{array}{l}\text { Stator end } \\
\text { winding }\end{array}$} & 200 & 193,7 & $3,3 \%$ \\
\cline { 2 - 4 } $\begin{array}{l}\text { Stator winding } \\
\text { inside slots }\end{array}$ & 200 & 195,2 & $2,5 \%$ \\
\cline { 2 - 4 } & 196 & 186,7 & $5,0 \%$ \\
\hline Frame & 196 & 178,9 & $9,6 \%$ \\
\hline Stator teeth & 192 & 130,2 & $7,8 \%$ \\
\hline
\end{tabular}

Table II. Temperatures at different points of the car alternator. The first colum is for temperatures computed using Opera2D in axi-symmetrical section.

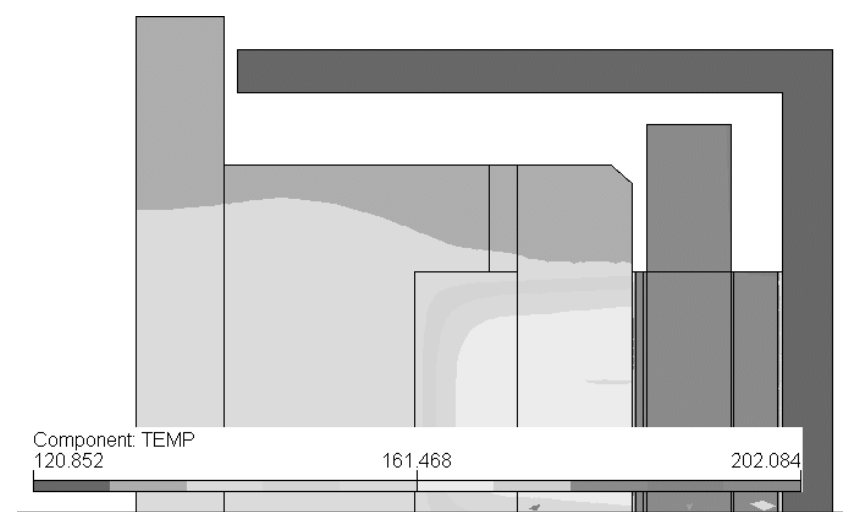

Fig. 10. Temperatures computed with Opera2D in axisymmetrical section.

\section{Kirchhoff network}

Because thermic simulation using the finite element method gave good results in axi-symmetrical section, a Kirchhoff network is constructed by neglecting the temperature variation in direction $\theta$. On the other hand, exchanges on the outside faces are taken into account in all the directions.

Iron losses are neglected to simplify the network and a resistance is introduced only if the gradient of temperature is superior to $10^{\circ} \mathrm{C}$. Exchanges on the outside faces are supposed to be essentially convective.

Capacities are present on the network to take into account the thermic inertia of materials during thermic transients. Finally, the Kirchhoff network includes 18 resistors, 3 current feedings, 5 capacities and 2 different voltage feedings (Fig. 11). In Table III, the maximal error between calculated temperatures using Kirchhoff's network and those measured is equal to $3 \%$. 


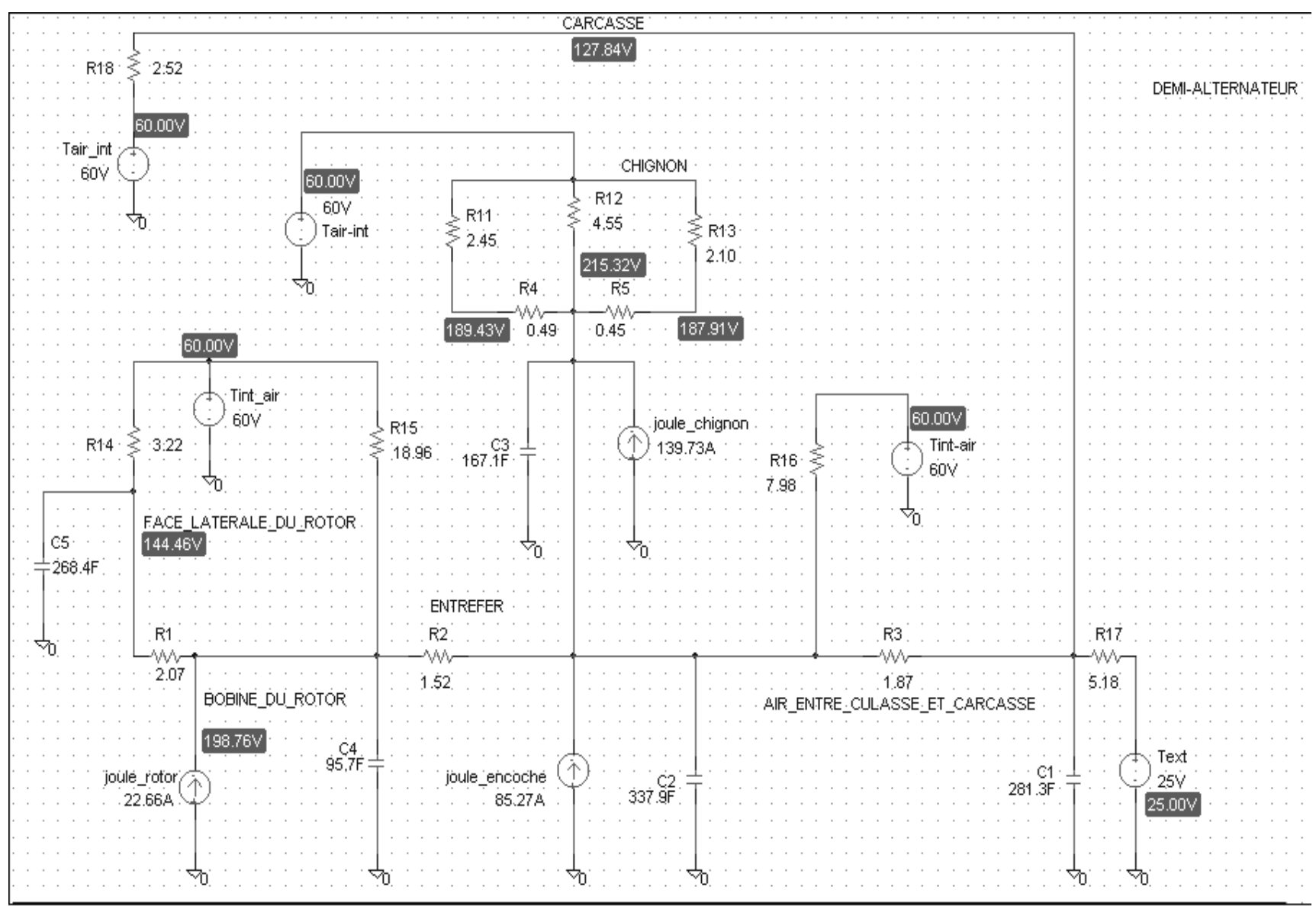

Fig. 11. Kirchhoff network for thermal simulation.

\begin{tabular}{l|cc|c}
\hline Temperatures & Network & Experiment & Error \\
\hline Stator end & 187,91 & 193,70 & $3,0 \%$ \\
\hline windings & 189,43 & 195,20 & $3,0 \%$ \\
\hline Frame & 127,84 & 130,20 & $1,8 \%$ \\
\hline
\end{tabular}

stator current are also accurate.

Table III. Temperatures at different points of the car alternator. The first colum is for temperatures computed using the Kirchhoff network.

\section{Conclusion}

The thermal modelling using a 2D finite element software enabled a compromise between the accuracy of the results and the modeling time. Thanks to thermal hybrid conductivities, the thermic simulation using Opera2D in axi-symmetrical section leads to good results.

Moreover, this simulation helps in the construction of a Kirchhoff network for the thermal study of the machine because it provides evidence that there are regions having a significant gradient of temperature. The network of thermic resistors offers at the same time a very short calculation time and a good accuracy. Its use is well suited to the design of car alternators.

The thermal modelling of the car alternator have been computed for a single shaft speed. Results for a different

\section{References}

Hecquet, M. and Brochet, P. (1995), « Modelling of a claw-pole alternator using permeance network coupled with electric circuit», IEEE Trans. On Magnetics, May 1995, Vol. 31 No. 3, pp. 2131-2134.

Vector Fields, (1999), OPERA-2D - User guide, Vector Fields Limited, 24 Bankside, Kidlington, Oxford OX5 1JE, England.

Bertin, Y. (1998), «Refroidissement des machines tournantes », Techniques de l'Ingénieur, D3 460.

Glises, R. (1998), «Machines électriques tournantes : simulation du comportement thermique », Techniques de l'Ingénieur, D3 760.

Sacadura, J.F. (1982), Initiation aux transferts thermiques, Tec\&Doc.

Ziouchi, A. (1996), Contribution à l'analyse et à la modélisation des échanges convectifs dans un entrefer de moteur électrique fermé, Thèse de l'Université de Poitiers. 
